\title{
Knowledge Sharing Through Enterprise Social Media in a Telecommunications Context
}

\author{
Hajir Al-Mawali, Sultan Qaboos University, Oman \\ Kamla Ali Al-Busaidi, Sultan Qaboos University, Oman*
}

\begin{abstract}
This study investigated the motivators of sharing knowledge through enterprise social media (ESM) in the telecommunications context. A questionnaire was distributed among knowledge workers in one of the leading telecommunication companies in the Sultanate of Oman. Based on the structural equation modelling-partial least squares (SEM-PLS) analysis of 100 responses from knowledge workers, results showed that technological motivators had significant effects on knowledge workers' knowledge sharing through ESM. Further analysis based on the knowledge type indicated that technological motivators and organizational motivators significantly impact knowledge workers' tacit knowledge sharing, whereas only technological motivators impact knowledge workers' explicit knowledge sharing. This study provides decision makers with useful insights on the motivators of sharing knowledge through ESM and further advances knowledge workers' learning and business operations, especially in under-investigated countries.
\end{abstract}

\section{KEYWORDS}

Enterprise Social Media, Knowledge Sharing, Knowledge Sharing Motivators, Knowledge Workers, Quantitative Study, Social Media, Telecommunications Company

\section{INTRODUCTION}

Knowledge is recognized as a vital element for organizations in the pursuit and gain of competitive advantage (Nguyen \& Prentice, 2020; Asrar-ul-Haq \& Anwar, 2016; Davenport \& Prusak, 1998). It is the key factor leading to innovation (Drucker, 1999), decision making (Al-Busaidi \& Olfman, 2017), improving a firm's performance, and creating value (Bock et al., 2005). The secret of any firm's success is in capitalizing on its knowledge as an intellectual asset rather than its physical assets (Davenport \& Prusak, 1998). Knowledge is a valuable resource because it critically focuses on taking the most effective action regarding the uncertainties in a business environment.

The concept of knowledge management (KM) has been defined as handling and improving the process of creating, distributing, and sharing knowledge within an organization (Bock et al., 2005; Davenport \& Prusak, 1998). Knowledge sharing (KS) is defined as process of transferring knowledge between individuals, groups, departments, or across all levels of an organization (Davenport \& Prusak, 1998; Nonaka \& Takeuchi, 1995), allowing workers to solve problems and provide new ideas. It communicates both tacit and explicit knowledge between individuals, allowing an effective transfer 
of knowledge to take place between individuals and across groups, departments, and organizations (Becerra-Fernandez \& Sabherwal, 2014).

Information and communication technology (ICT), which is immensely valued, has experienced enormous growth since the 1990s. ICT provides optimal value in facilitating KS in two ways: by storing explicit knowledge and by improving the efficiency of transferring the knowledge. Social media is web 2.0, which refers to the technologies and collaborative online applications that motivate people to participate, share their knowledge, and contribute to solving issues and proposing new ideas (Meneghello et al., 2020). As such, social media embraces tools such as YouTube, LinkedIn, Facebook, Twitter, Snapchat, Tencent, and WeChat. Enterprise social media (ESM) has been introduced to democratize participation among employees to share experience and knowledge across organizational boundaries without being constrained by hierarchical and geographical boundaries (Lacosta \& Thomas, 2020; Rozaidi et al., 2017). ESM consists of web-based platforms that allow active participation between co-workers through posting, editing, viewing, and sorting text and files with a specific co-worker or broadcasting a message to anyone in the organization at any time (Rahman, 2020; Wei et al., 2020; Leonardi et al., 2013).

$\mathrm{KM}$ in the telecommunications industry is considered to be a competitive weapon that enables a company to survive and stay ahead in the era of knowledge-based economy. In line with this, some western telecommunications companies have created a new position in their organizations called Chief Knowledge Officer to assure that KM operates effectively in terms of capturing and sharing knowledge to be used as intellectual assets (Strouse, 2001).

Reports have indicated that little attention has been given to the use of social media to facilitate internal organizational activities such as collaboration and KS and, thus, further studies may focus on exploring and investigating this subject within the Information Systems(IS) research field (Laitinen \& Sivunen, 2021; Aboelmaged, 2018; Pérez-González et al., 2017; Scuotto et al., 2017; Al-Busaidi, 2014). Moreover, Aboelmaged (2018) revealed that enterprise social network (ESN) platforms like Yammer are a novel phenomenon, showing that little is known about the motivators that affect how employees share knowledge using enterprise social networks. In another study, McKinsey observed an increase in knowledge worker productivity of around 20-25\% because of using social technologies (Bughin et al., 2012). Thus, enterprise social media (ESM) has been introduced to democratize participation among employees to share experience and knowledge across organizational boundaries without being constrained by hierarchical and geographical boundaries (Rozaidi et al., 2017). The need for such research has also been highlighted by Chin et al. (2015) and Rozaidi et al. (2017). This investigation contributes to learning how to motivate employees to share knowledge for work purpose, and can be used to overcome barriers (Razmerita et al., 2016; Laitinen \& Sivunen, 2021).

The aim of this study is to investigate the motivators that impact knowledge workers' usage of enterprise social media (ESM) to share knowledge in a telecommunications company. In addition, this study will assist organizations in employing enterprise social media technologies as an effective means of communicating between employees and boosting the KS among them. Therefore, to respond to the call for future research in the field of telecommunications, this paper investigates the motivators for knowledge workers in using ESM to share knowledge in a telecommunications company. The telecommunications sector was selected, as it is one of the fastest-growing sectors across the world and is regarded as being an intensive knowledge-based sector that seeks a high level of KS from its employees (Nguyen et al., 2021; Akram et al., 2017; Chin Wei et al., 2009; Hsu \& Chang, 2014). To sustain their competitive advantages, telecommunications companies should motivate their employees to share knowledge and innovate (Akram et al., 2017; Ibidunni et al., 2018; Stephen et al., 2018); thus, it is crucial to investigate the factors that affect employees' KS. Telecommunication firms should exploit the affordances enabled by ESM to capture their employees' expertise and skills to survive in a competitive market. 


\section{Background}

\section{ENTERPRISE SOCIAL MEDIA (ESM)}

Leonardi et al. (2013) defined enterprise social media (ESM) as "web-based platforms that allow workers to (1) communicate messages with specific coworkers or broadcast messages to everyone in the organization; (2) explicitly indicate or implicitly reveal particular coworkers as communication partners; (3) post, edit, and sort text and files linked to themselves or others; and (4) view the messages, connections, text, and files communicated, posted, edited, and sorted by anyone else in the organization. Several researchers have asserted that ESM affords the visibility and persistence of content published by users by integrating communication, collaboration, and a document repository system into a single platform. Furthermore, ESM increases the opportunities of social interaction and learning by expanding to a wide range of individuals and networks, thus facilitating organizational KS by enabling individuals to locate and share expertise (Lacosta \& Thomas, 2020; Wei et al., 2020; Aboelmaged, 2018; Leonardi et al., 2013). Majchrzak et al. (2013) emphasized the affordances enabled by ESM for KS within organizations. In addition, security concerns are one of the primary reasons to keep social media that is not accessible to external audiences within the enterprises themselves. ESM can be either open source, hosted as "software as a service" (SaaS), or constructed as an enterprise proprietary system. Many enterprise social software tools include a full functionality of social media features, such as, wikis, blogs, status updates, micro blogs, uploading and sharing files, social analytics, and social network features (creating profiles and the ability to follow other co-workers) (Leonardi et al., 2013). Examples of professional ESM include Salesforce's Chatter, IBM's Social Blue, Socialtext, MediaWiki, IBM's Dogear, Microsoft's SharePoint, Yammer, IBM's Connections, Jive from Jive Software, PARC's SparTag, Oracle's Social Network, Cisco's WebEx Social, eXo Platform, Telligent, Socialcast, and Ingage Networks (Rahman, 2020; Wei et al., 2020; Aboelmaged, 2018; Leonardi et al., 2013).

Prior research has highlighted several benefits of using ESM for KS. Aboelmaged (2018) studied employees' use of an enterprise social network (ESN) for KS activities such as idea generation, sharing files or photos, and searching or asking for specific information. Leonardi (2017) explored how the communication visibility afforded by ESN fosters organizational metaknowledge (i.e., knowledge of who knows what and who knows who) and reduces knowledge redundancy, thus contributing to employees' innovativeness and effectiveness in learning new ways of working. Thus, the use of ESM can generate opportunities for telecommunications companies.

\section{KM IN THE TELECOMMUNICATIONS INDUSTRY}

The telecommunications sector has been recognized as a major contributor to economic growth due to the emergence of the knowledge-based economy, in which employees are required to share knowledge to survive in a highly competitive market (Akram et al., 2017). AlRowaily and Alsadhan (2012) and Ibidunni et al. (2018) highlighted that the telecommunications industry is knowledgebased due to the rapid growth of driven technology and innovation within the field. Studies in the literature thus far on $\mathrm{KM}$ in the telecommunications industry have demonstrated the importance of KM on customer satisfaction (AlRowaily \& Alsadhan, 2012; Stephen et al., 2018) and organization performance (Suraj, 2016).

Telecommunications companies demand a high level of investment in knowledge-based resources and capabilities (Ibidunni et al., 2018), as human capital is considered to be a source of innovation through the exploitation of the knowledge of its employees (Suraj, 2016). Hence, telecommunications companies must capture their employees' expertise, skills, and experience (AlRowaily \& Alsadhan, 2012) by engaging the workers to share tacit and explicit knowledge (Ibidunni et al., 2018). This is 
important because knowledge is a strategic resource and must be in alignment with the company's strategic direction (Ibidunni et al., 2018). The basic idea, according to Stephen et al. (2018), is that employees at telecommunications companies should be motivated to use their tacit knowledge, which consists of most innovative behaviors and know-how knowledge that can be difficult to articulate. Innovation capacity within telecommunications companies can be enhanced if they invest in an efficient KM infrastructure, mainly in information technology, to achieve a sustainable competitive advantage in the industry. Therefore, it is vital for telecommunications companies to determine what factors influence employees' KS (Akram et al., 2017).

\section{PRIOR STUDIES}

Ample research has explored the motivational factors of KS attitudes, as well as intentions and behaviors in general, in organizational settings. Previous literature has recognized various motivators that influence an individual's KS among different industry sectors and cultures. These motivational factors can be grouped into several categories: organizational factors, individual factors, technological factors, and peer factors (Al-Busaidi, 2015; Al-Busaidi \& Olfman, 2017; Chennamaneni et al., 2012; Nielsen \& Razmerita, 2014; Razmerita et al., 2016), as indicated in Table 1. The majority of the studies were conducted using quantitative approaches. From the literature review, it is clear that common motivators are revealed through studying the motivators of KS in general, motivators of $\mathrm{KS}$ through the use of social media, and motivators of KS in telecommunications companies. These can be grouped into individual motivators (e.g., reputation, knowledge self-efficacy, enjoyment in helping others, and reciprocal benefits), peer motivators (e.g., social interaction, trust, employees' KS interactivity, and peers' attitudes), organizational motivators (e.g., management support, rewards, organizational culture, and organizational structure), and technological motivators (e.g., perceived usefulness, perceived ease of use, technology task fit, and perceived security). Table 1 illustrates the motivators related to all the categories, including study references.

\section{RESEARCH FRAMEWORK}

\section{Framework Development}

As mentioned earlier, this research aims to investigate knowledge workers' motivators to use ESM for KS in a telecommunications company. Thus, based on the above literature review, a research framework has been developed. These motivators are shown in Figure 1.

\section{Individual Motivators}

Several individual motivators can impact knowledge workers' KS through ESM. These individual motivators include reputation, knowledge self-efficacy, enjoyment in helping others, and reciprocal benefits.

Reputation: Reputation is a significant extrinsic motivator for KS. It is an important asset for individuals in leveraging their social recognition and status among their peers (Davenport \& Prusak, 1998; Kankanhalli et al., 2005; Welschen, 2014). Using the setting of a large Russian telecommunications company, Rozaidi et al. (2017) stressed how contributor status level motivates employees to use ESM for sharing ideas and Q\&A sessions.

Knowledge self-efficacy: Self-efficacy refers to the self-evaluation of individuals regarding their capabilities, skills, and competence to adopt a specific behavior in order to perform a certain task (Lin, 2007). Prior studies have observed that the more individuals have knowledge self-efficacy, the more willing they are to share their knowledge (Maheshwari et al., 2021; Lin, 2007). Employees' self-efficacy in terms of confidence and ability positively motivates them to share knowledge through 
Table 1. Overview of All Knowledge Sharing Motivators

\begin{tabular}{|c|c|c|c|}
\hline Motivators & KM References & Social Media References & Telecom References \\
\hline \multicolumn{4}{|l|}{ Individual Motivators } \\
\hline Reputation & $\begin{array}{l}\text { Welschen (2014), Chennamaneni et al. } \\
\text { (2012), Hung et al. (2011), van Dijk et al. } \\
\text { (2016), Kankanhalli et al. (2005) }\end{array}$ & $\begin{array}{l}\text { Rode (2016), Chin, et al., (2015), Oh } \\
\text { and Syn (2015), Leonardi (2017), } \\
\text { Wang et al. (2014) }\end{array}$ & $\begin{array}{l}\text { Razmerita et al. (2016), Rozaidi } \\
\text { et al. (2017). }\end{array}$ \\
\hline Knowledge Self-efficacy & $\begin{array}{l}\text { Welschen (2014), Lin (2007), Cabrera et al. } \\
\text { (2006), Kankanhalli et al. (2005) }\end{array}$ & $\begin{array}{l}\text { Maheshwari et al. (2021), Ahmed } \\
\text { et al. (2016), Rode (2016), Oh and } \\
\text { Syn (2015) }\end{array}$ & $\begin{array}{l}\text { Nguyen et al. (2021), Susanty } \\
\text { et al. (2016), Chin et al. (2015) }\end{array}$ \\
\hline Enjoyment in helping others & $\begin{array}{l}\text { Hau et al. (2013), Chennamaneni et al. } \\
\text { (2012), Hung et al. (2011), Lin (2007), } \\
\text { Kankanhalli et al. (2005) }\end{array}$ & $\begin{array}{l}\text { Ahmed et al. (2016), Chin et al., } \\
\text { (2015), Oh and Syn (2015), Yu et } \\
\text { al. (2010) }\end{array}$ & $\begin{array}{l}\text { Nguyen et al. (2021), } \\
\text { Razmerita et al. (2016). } \\
\text { Susanty et al. (2016), Chin } \\
\text { et al., (2015), Kanaan and } \\
\text { Gharibeh (2013), Masa'deh } \\
\text { et al. (2013) }\end{array}$ \\
\hline Reciprocal benefits & $\begin{array}{l}\text { van Dijk et al. (2016), Welschen (2014), Hau } \\
\text { et al. (2013), Chennamaneni et al. (2012), } \\
\text { Hung et al. (2011), Lin (2007), Kankanhalli } \\
\text { et al. (2005) }\end{array}$ & $\begin{array}{l}\text { Maheshwari et al. (2021), Rode } \\
\text { (2016), Chin et al., (2015), Oh and } \\
\text { Syn (2015) }\end{array}$ & Nguyen et al. (2021) \\
\hline \multicolumn{4}{|l|}{ Peers Motivators } \\
\hline Social interaction & $\begin{array}{l}\text { Borges et al. (2019), Asrar-ul-Haq and Anwar } \\
\text { (2016), van Dijk et al. (2016), Zhang and } \\
\text { Jiang (2015), Hau et al. (2013), Ghobadi and } \\
\text { D'Ambra (2012), Al-Alawi et al. (2007) }\end{array}$ & $\begin{array}{l}\text { Aboelmaged (2018), Oh and Syn } \\
\text { (2015), Chin et al., (2015), Wang et } \\
\text { al. (2014) }\end{array}$ & Chin et al., (2015) \\
\hline Trust & $\begin{array}{l}\text { Javaid et al. (2020), Asrar-ul-Haq and Anwar } \\
\text { (2016), Hau et al. (2013), Al-Alawi et al. } \\
\text { (2007),Kankanhalli et al. (2005) }\end{array}$ & Ahmed et al. (2016), Harden (2012) & Iqbal et al. (2015) \\
\hline $\begin{array}{l}\text { Employees' knowledge } \\
\text { sharing interactivity }\end{array}$ & Welschen, (2014) & $\begin{array}{l}\text { Leonardi (2017), Chin et al., (2015), } \\
\text { Harden (2012) }\end{array}$ & $\begin{array}{l}\text { de Almeida et al. (2016), } \\
\text { Iqbal et al. (2015), Chin et } \\
\text { al., (2015). }\end{array}$ \\
\hline Peers' attitude & Zhang and Jiang (2015) & Wang et al. (2014), Harden (2012) & Nguyen et al. (2021) \\
\hline \multicolumn{4}{|l|}{ Organizational Motivators } \\
\hline Management support & $\begin{array}{l}\text { Asrar-ul-Haq and Anwar (2016), Yeo and Gold } \\
\text { (2014).Al-Busaidi et al. (2010), Cabrera et } \\
\text { al. (2006). }\end{array}$ & Ahmed et al. (2016), Chin et al., (2015). & $\begin{array}{l}\text { Razmerita et al. (2016), de } \\
\text { Almeida et al. (2016), Susanty } \\
\text { et al. (2016), Nielsen and } \\
\text { Razmerita (2014), Kanaan } \\
\text { and Gharibeh (2013), } \\
\text { Masa'deh et al. (2013), Chin } \\
\text { et al., (2015). }\end{array}$ \\
\hline Rewards & $\begin{array}{l}\text { Javaid et al. (2020), Yeo and Gold (2014), } \\
\text { Hau et al. (2013), Al-Busaidi et al. (2010), } \\
\text { Al-Alawi et al. (2007). Cabrera et al. (2006), } \\
\text { Kankanhalli et al. (2005), Stenius et al. (2017). }\end{array}$ & $\begin{array}{l}\text { Ahmed et al. (2016), Chin et al., } \\
\text { (2015), Oh and Syn (2015) }\end{array}$ & $\begin{array}{l}\text { Nguyen et al. (2021), } \\
\text { Nguyen and Prentice } \\
(\mathbf{2 0 2 0 )}, \text { Razmerita et al. } \\
(2016), \text { Susanty et al. (2016), } \\
\text { Iqbal (2016), Nielsen and } \\
\text { Razmerita (2014), Kanaan } \\
\text { and Gharibeh (2013), } \\
\text { Masa'deh et al. (2013) }\end{array}$ \\
\hline Organizational culture & $\begin{array}{l}\text { Javaid et al. (2020), Borges et al. (2019), } \\
\text { Asrar-ul-Haq and Anwar (2016), Yeo and Gold } \\
\text { (2014). Chennamaneni et al. (2012), Chen et } \\
\text { al. (2012), Stenius et al. (2017), Kankanhalli } \\
\text { et al. (2005) }\end{array}$ & $\begin{array}{l}\text { Yu et al. (2010), } \\
\text { Chin et al., (2015). }\end{array}$ & $\begin{array}{l}\text { Chin et al., (2015).Nielsen and } \\
\text { Razmerita (2014) }\end{array}$ \\
\hline Structure & $\begin{array}{l}\text { Asrar-ul-Haq and Anwar (2016), Al-Alawi et } \\
\text { al. (2007) }\end{array}$ & & Cummings (2004) \\
\hline \multicolumn{4}{|l|}{ Technological Motivators } \\
\hline Perceived usefulness & $\begin{array}{l}\text { Welschen (2014), Hung et al. (2011), Xu and } \\
\text { Quaddus (2007) }\end{array}$ & $\begin{array}{l}\text { Ahmed et al. (2016), Wang et al. } \\
\text { (2014), Oh and Syn (2015), Leonardi } \\
\text { (2017), Yu et al. (2010) }\end{array}$ & $\begin{array}{l}\text { Nielsen and Razmerita } \\
\text { (2014), Chin et al., (2015), }\end{array}$ \\
\hline Perceived ease of use & Hung et al. (2011), Xu and Quaddus (2007) & $\begin{array}{l}\text { Ahmed et al. (2016), Chin et al., } \\
\text { (2015), Wang et al. (2014) }\end{array}$ & Chin et al., (2015). \\
\hline
\end{tabular}


Table 1. Continued

\begin{tabular}{|l|l|l|l|}
\hline Motivators & KM References & Social Media References & Telecom References \\
\hline Technology task fit & $\begin{array}{l}\text { Stenius et al. (2017), Ghobadi and D'Ambra } \\
\mathbf{( 2 0 1 2 )}\end{array}$ & Chin et al., (2015) & \\
\hline Perceived security & $\begin{array}{l}\text { Chen (2008), Jennex and Zyngier (2007), Xu } \\
\text { and Quaddus (2007) }\end{array}$ & $\begin{array}{l}\text { Choudrie and Zamani (2016), Wang } \\
\text { et al. (2014) }\end{array}$ & \\
\hline $\begin{array}{l}\text { References Note: Bold = Quantitative, Italic = Qualitative, Standard = literature review, Underline = Mixed } \\
\text { Methodology, Strikethrough = Theoretical, Italic and Underline = Experiment. }\end{array}$
\end{tabular}

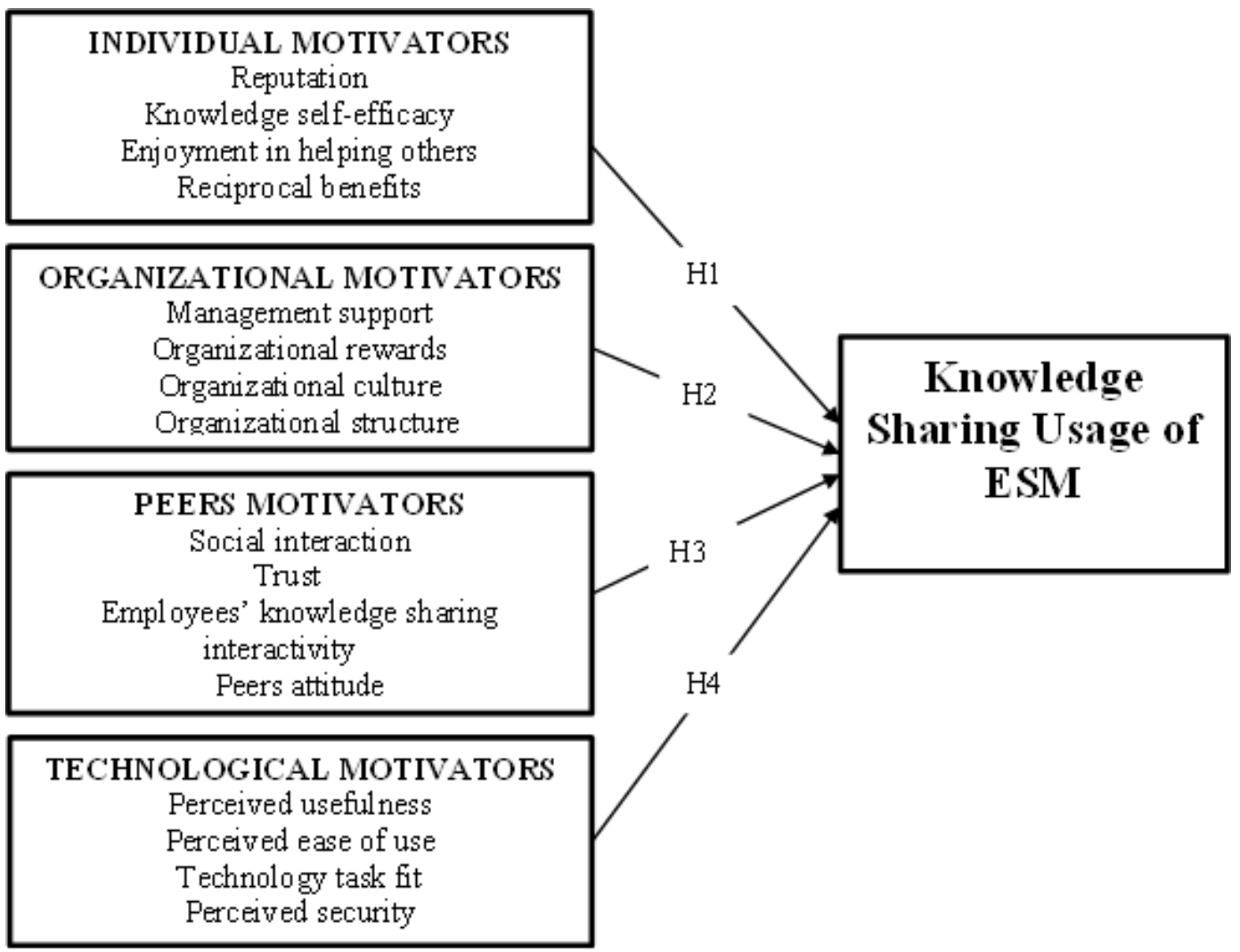

ESM (Rode, 2016) and to share knowledge and facilitate communication through ESM in the context of a telecommunications company (Chin et al., 2015),

Enjoyment in helping others: In general, "enjoyment" refers to "the extent to which [an] activity (...) is perceived to be enjoyable in its own right, apart from any performance consequences that may be anticipated" (Davis et al., 1992). Prior studies have indicated that enjoyment in helping others motivates individuals to share knowledge in electronic knowledge repositories (Hung et al., 2011), enterprise social networks (Chin et al., 2015), and telecommunications companies (Nguyen et al., 2021; Razmerita et al., 2016; Susanty et al., 2016; Kanaan \& Gharibeh, 2013). 
Reciprocal benefits: Reciprocity can occur directly between two parties or to a wider community of individuals. While, in the former case, the other individual will receive the benefit directly, i.e., "I help you, and you help me or someone else in return" (Rode, 2016), Hau et al. (2013) provided empirical evidence that reciprocal benefits significantly influence individuals' explicit and tacit KS intentions. Rode (2016) found that the more employees believe that KS results in reciprocal benefits, the more willing and likely they are to share knowledge on ESM platforms.

H1. Individual motivators are significantly associated with knowledge workers' knowledge sharing through ESM.

\section{Organizational Motivators}

Several organizational motivators can impact knowledge workers' KS through ESM. These organizational motivators include management support, rewards, organizational culture, and organizational structure.

Management support: The more positive the support provided by management and supervisors is, the more inclined the individual is to perform certain behaviors in the workplace, such as KS, in KM systems (Cabrera et al., 2006); public and private social media platforms, such as bogs, Yammer, etc. (Chin, Evans, \& Choo, 2015; Razmerita et al., 2016); and telecommunications companies through the use of social media (Nielsen \& Razmerita, 2014).

Rewards: Prior studies (e.g., Yeo and Gold, 2014; Hau et al., 2013; Al-Busaidi et al., 2010) have suggested that rewards motivate the willingness to engage in KS behaviors. Rewards can be tangible/ monetary, such as bonuses, job security, and promotions (Nguyen \& Prentice, 2020, Chennamaneni et al., 2012; Kankanhalli et al., 2005), or intangible/non-monetary, such as feedback, praise, and recognition (Nguyen \& Prentice, 2020; Welschen, 2014). Razmerita et al. (2016) highlighted the positive impact of monetary rewards on knowledge workers' KS behaviors through ESM in different sectors, including the telecommunications sector. Intrinsic rewards have been proven to encourage KS participants (knowledge donators, collectors, and lurkers) to share their knowledge online (Nguyen \& Prentice, 2020).

Organizational culture: Norms, values, and beliefs observed by organizational employees reflect/represent organizational culture. An organizational culture with openness and fairness fosters the sharing of knowledge, which leads to the creation of an innovative culture that emphasizes the enhancement of employees' creativity, finding solutions together with other co-workers, and sharing knowledge (Asrar-ul-Haq \& Anwar, 2016). These findings have also been demonstrated in the telecommunications sector (Chin et al., 2015).

Organizational Structure: Organizational structure is important in sharing knowledge, particularly tacit knowledge, and in leveraging technological architecture (Gold et al., 2001). Creating a flexible organizational structure and relationship network of professionals facilitates individuals to locate the expertise and "know-what" to ease the process of KS across the organization (Asrar-ul-Haq \& Anwar, 2016) by reducing the boundaries across organizational levels (Gold et al., 2001). Cummings (2004) found that the more diverse the structure of the work group in a telecommunications firm, the more motivated individuals will be to share knowledge.

H2. Organizational motivators are significantly associated with knowledge workers' knowledge sharing through ESM.

\section{Peer Motivators}

Several peer motivators can impact knowledge workers' KS through ESM. These organizational motivators include social interaction, trust, employees' interactivity, and peers' attitudes. 
Social interaction: Social interaction brings opportunities for organizations to perform in such a way as to obtain knowledge from knowledge holders and gain benefits from each other (Asrar-ul-Haq \& Anwar, 2016). The fun and joy in social interaction are found to be positively related to individuals' KS behavior through ESM (Aboelmaged, 2018; Wang et al., 2014). This has also been demonstrated in telecommunications companies (Chin et al.,2015).

Trust: Kankanhalli et al. (2005) insightfully pointed out that employees are less likely to use electronic knowledge repositories to share knowledge when there is a lack of trust between the other employees regarding contributing and seeking knowledge, taking into account the perceived effort and time to codify the knowledge. The trustworthiness of social media is now a crucial consideration. Due to the massive volume of interchanged data within social media, data credibility and trustworthiness is a vital issue (Abu-Salih et al., 2019). Therefore, researchers have found that trust has an essential positive effect on individuals' intention to use SNS for KS (Harden, 2012) and on individuals' KS behavior in the telecommunications sector (Iqbal et al., 2015).

Employees' KS interactivity: This refers to individual participation, engagement, and teamwork to achieve common goals within organizations. Research has found that individuals realize that their knowledge is valuable and leads to the desired outcomes when others provide feedback on their contributions through different social media platforms (Leonardi, 2017). Researchers (de Almeida et al., 2016; Iqbal et al., 2015) have found that, in the educational and telecommunication sectors, individuals' collaborations through ESM significantly affect KS behaviors and consequently improve their professional relationships.

Peers' attitudes: Peers' attitudes towards KS affects individuals' KS. If individuals find that their colleagues value a technology, then they may also convince themselves to use that technology (Al-Busaidi \& Olfman, 2017; Harden, 2012). In the context of enterprise 2.0 applications, Wang et al. (2014) found that subjective norms affect individual behavior intentions to use enterprise 2.0 applications such as blogs, wikis, and ESNs for KS and collaboration. A recent study conducted in Vietnamese telecommunications companies found that subjective norms motivate employees, both posters and lurkers, to share knowledge using different online KS platforms (OKS) such as weblogs, intranets, and forums (Nguyen et al., 2021).

H3. Peer motivators are significantly associated with knowledge workers' knowledge sharing through ESM.

\section{Technological Motivators}

Several technological motivators can impact knowledge workers' KS through ESM. These organizational motivators include perceived usefulness, perceived ease of use, technology task fit, and perceived security.

Perceived usefulness: Perceived usefulness refers to an individual's belief and expectations regarding using the system to improve job performance (Davis et al., 1992). In the context of KS behavior, perceived usefulness refers to the knowledge sharer's belief that KS can improve efficiency and generate benefits for individuals involved (Al-Busaidi \& Olfman, 2017; Kankanhalli et al., 2005). This includes the use of ESM in the telecommunications sector (Nielsen \& Razmerita, 2014).

Perceived ease of use: Perceived ease of use refers to an individual's belief such a system would be effortless and easy to use (Davis et al., 1992). The ease of learning and having a user-friendly knowledge management system (KMS) impacts the end users' adoption of KMS (Xu and Quaddus, 2007). Hung et al. (2011) found that perceived ease of use positively impacts individuals' intentions of using KMS. Similarly, in the social media context, perceived ease of use in terms of creating and retrieving content significantly impacts knowledge workers when using ESN for KS (Chin, Evans, $\&$ Choo, 2015). This has also been demonstrated in a telecommunications company, as studied by Chin, Choo et al. (2015). 
Technology task fit: Goodhue and Thompson (1995) defined task technology fit as the way technology can help individuals by supporting their tasks. User acceptance of a technology has been linked to job relevance, based on task technology fit research conducted by Goodhue and Thompson (1995). Job design in terms of identifying relevant activities and tasks for the employees within the organization leads to motivational consequences to sharing their knowledge. In the ESN context, Chin, Evans, and Choo (2015) have indicated that employees are motivated to complete their tasks using ESN for KS.

Perceived security: Perceived security is the individual's belief that using information technology (IT) is free of risk (Wang et al., 2014). Thus, having proper security measures in KMS is critical in KS activities to prevent unauthorized access (Xu \& Quaddus, 2007; Al-Busaidi and Olfman (2017)). Studies have confirmed the importance of security for using ESM (Choudrie \& Zamani, 2016; Wang et al., 2014). In addition, Choudrie and Zamani (2016) have indicated how Yammer is an effective system, as it allows only authorized individuals to access online content and has a realistic recordkeeping feature.

H4. Technological motivators are significantly associated with knowledge workers' knowledge sharing through ESM.

\section{Knowledge Sharing Dependent Variable}

Prior studies have investigated KS based on attitude, as in Yeo and Gold (2014); intention, as in Chen et al. (2012), Harden (2012), and Wang et al. (2014); or actual KS behavior, as in Kankanhalli et al. (2005), Rode (2016), and Aboelmaged (2018).

In this study, KS will be assessed by knowledge workers' usage of ESM for KS, as Chennamaneni et al. (2012) recommended in order to study actual KS behavior. KS involves two sub-processes: exchange and socialization. Thus, the usage of ESM for KS will be assessed first in a general sense and then in depth to assess the actual usage of ESM from two dimensions (explicit and tacit knowledge), as used by Bock et al. (2005).

\section{METHODOLOGY}

\section{Participants and Data Collection}

This study collected data from knowledge workers in the telecommunications sector. The telecommunications sector is one of the fastest-growing sectors in the world and is regarded as being an intensive knowledge-based sector that seeks a high level of KS from its employees (Akram et al., 2017; Chin Wei et al., 2009).

"Knowledge workers" refers to individuals with high levels of creativity, formal education, and learning who apply analytical and theoretical knowledge to solving problems in their field of expertise (Drucker, 1994). Knowledge workers and their productivity have been regarded as the most valuable assets of the 21 st century, whether for business or non-business environments (Drucker, 1999). According to Lee and Maurer (1997), knowledge workers are key players in the firm because they add value by applying their knowledge effectively. The literature has identified some examples of knowledge workers, such as engineers, computer scientists, consultants, social scientists, and accountants (Lee \& Maurer, 1997). In the context of the telecommunications industry, Singh and Sharma (2011) have indicated other examples of knowledge workers, such as project managers, consultants, team members, researchers, and designers. Chennamaneni et al. (2012) also targeted knowledge workers such as specialists, engineers, and analysts in their study.

An electronic invitation message and online survey link were posted on the company's ESM (Yammer). The survey was distributed in the English language because English is the formal business communication language. Participation in the survey was voluntary. 


\section{Research Questionnaire}

To investigate the motivators of knowledge workers on KS in ESM, this study used a quantitative research approach by adopting a survey method to collect the data. Quantitative research approaches focus on testing the hypothesis to make a broad generalization (Creswell, 2003). Chennamaneni et al. (2012) numerically tested their research model and the associated hypothesis by conducting a survey in the form of a questionnaire specifically to investigate knowledge workers' intentions and behaviors towards sharing knowledge. Saunders et al. (2012) emphasized that using a survey as a research strategy enables the collection of quantitative data that can be used to numerically measure the relationship between variables. In addition, the nature of the research question implies the suitability of a quantitative approach. In contrast to the quantitative research approach, qualitative research aims to explore and describe a subject rather than measure and quantify it. Findings from qualitative research approaches, such as in-depth or semi-structured interviews, are likely to be a concern in that statistical generalizations are made about the entire population (Saunders et al., 2012).

The questionnaire included items and indicators related to the study constructs developed by modifying existing measures that were validated, proved, and utilized in previous studies. The dependent variable is "KS usage of ESM" and the independent variables are measured through a 5-point Likert scale ( $1=$ Strongly Disagree, $2=$ Disagree, $3=$ Neutral, 4= Agree and 5= Strongly Agree) anchored by adopting quantitative closed-ended questions. Furthermore, the study adopted open-ended questions to consider other motivators provided by the study participants. The questionnaire was designed to also collect demographic information, such as gender, age, work experience, and job title.

A pilot study was conducted to permit the researcher to assess the validity and reliability of the research questions and ensure high response rates from the data collected (Saunders et al., 2012). The questionnaire was sent to 15 participants within the telecommunications company being studied. The minimum sample size for a pilot study is 10, as recommended by Saunders et al. (2012). The appendix shows the construct measurements and sources for each item.

\section{Analysis Approach}

The approach used to analyze the quantitative data gathered was structural equation modeling (SEM) to estimate casual relationships between latent variables on a hypothesized model (Aboelmaged, 2018; Chin, 1998). One SEM technique is partial least squares (PLS), which is used to test hypotheses to indicate whether correlations exist (Chin, 1998). Compared to alternative structural equation modeling techniques, PLS is less sensitive to sample size (Aboelmaged, 2018; Bock et al., 2005; Chin, 1998).

Following the suggestions by Hair et al. (2016) and Bock et al. (2005), the PLS-SEM assessment employed a two-step building process to analyze the data: (1) assessing the quality of the measurement model, and (2) assessing the structural model by testing the research hypothesis.

\section{RESULTS AND DISCUSSION}

\section{Descriptive Statistics}

The questionnaire includes questions about KS activities. Figure 2 below displays the activities used to share knowledge through ESM among the telecommunications company staff. Around $62 \%$ of the participants have used ESM for task discussion (58\%), problem solving (58\%), and activities such as idea generation, sharing details/links, searching/asking for information, and clarifying an issue (41\% to $46 \%$ ). Activities such as informal chats, status updates and sharing a file/photo or announcements had similar frequency values, from $30 \%$ to $35 \%$. Sharing tips and tricks was reported by $26 \%$ of the participants, while praising and other activities were reported less frequently. 
Figure 2. Usage of ESM Activities in Knowledge Sharing

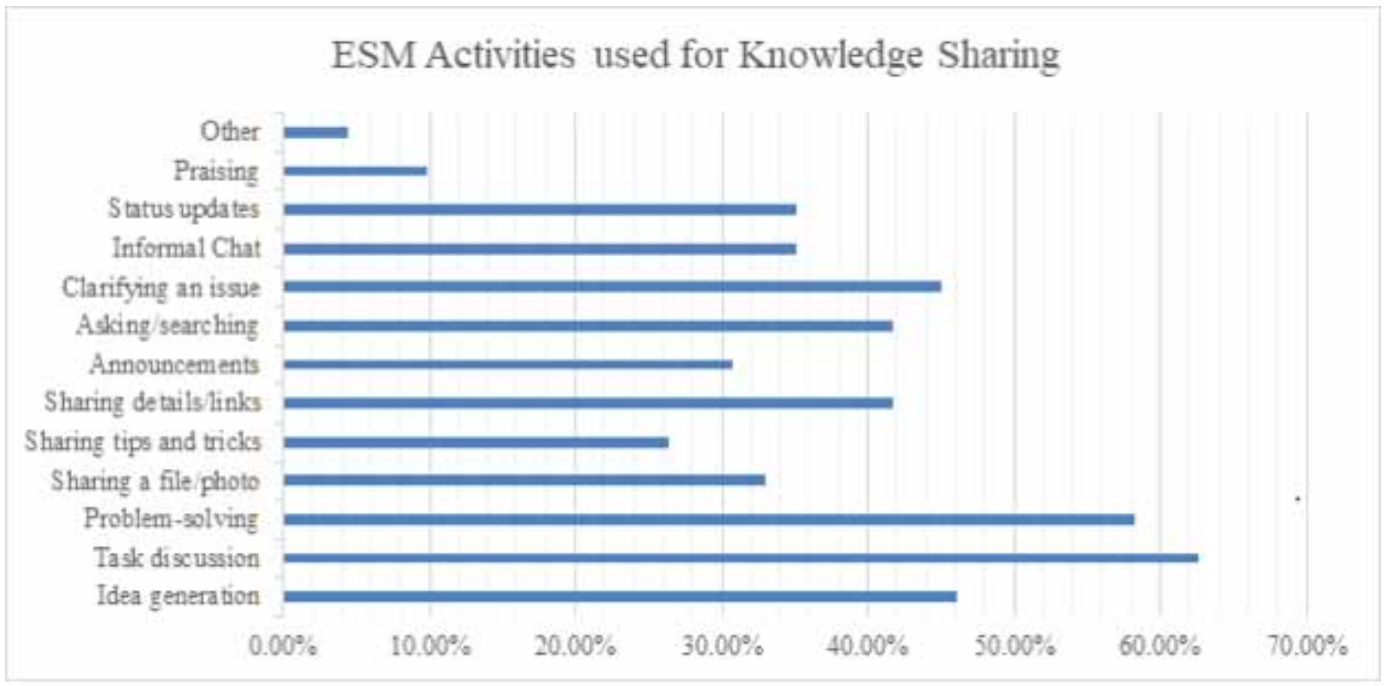

\section{Sample Profile}

This study targeted knowledge workers from one of the leading telecommunications companies in Oman. Furthermore, the company has deployed an ESM platform called "Yammer," which is used for collaboration and KS. This study targeted knowledge workers who are accessing and using ESM, particularly Yammer, in the telecommunications company. Access to Yammer in this telecommunications company is given to competent employees with valuable knowledge to contribute, and the company has implemented a mechanism to select employees based on their knowledge.

Table 2. Participants profile

\begin{tabular}{|l|l|l|l|l|}
\hline Gender & Percentage (\%) & & Total working experience & Percentage (\%) \\
\hline Male & $71 \%$ & & $<2$ years & $2 \%$ \\
\hline Female & $29 \%$ & & $<5$ years & $8 \%$ \\
\hline Education & & $<10$ years & $25 \%$ \\
\hline High school & $1 \%$ & $<15$ years & $33 \%$ \\
\hline Diploma & $3 \%$ & $<20$ years & $20 \%$ \\
\hline Bachelor's degree & $58 \%$ & $>=20$ years & $12 \%$ \\
\hline Master's degree & $37 \%$ & Total years of using ESM & \\
\hline Ph.D. & $1 \%$ & Not use at all & $7 \%$ \\
\hline Age Group & & $<=6$ months & $24 \%$ \\
\hline $20-<30$ years & $8 \%$ & $<1$ year & $45 \%$ \\
\hline $30-<40$ years & $57 \%$ & $<2$ years & $7 \%$ \\
\hline $40-<50$ years & $35 \%$ & $<3$ years & $4 \%$ \\
\hline & & $>=3$ years & $13 \%$ \\
\hline
\end{tabular}


An invitation message about the study was posted on Yammer for the entire company. The invitation message briefly explained the purpose of conducting the study and contained an online survey link to participate in the survey. About 137 employees participated in the web-based survey, but only 100 responses were valid. Table 2 shows the profile of the participants.

\section{Assessment of the Measurement Model}

Multiple measurements were used to measure the adequacy of the measurement model. Based on the initial analysis, the finalized model used all the constructs except for the Enjoyment, Peers'_Trust and Social_Interaction constructs due to low indicator loadings.

\section{Internal Consistency Reliability}

Table 3 shows internal consistency reliability results as the composite reliability (CR) for all the constructs that exceeded the recommended value of 0.70 , where the majority of the constructs above 0.900 demonstrate very strong internal consistency reliability (Chennamaneni et al., 2012).

Table 3. Study Model - Constructs' Reliability and Validity

\begin{tabular}{|c|c|c|c|}
\hline Construct & No. of Items & Composite Reliability & AVE \\
\hline \multicolumn{4}{|c|}{ Individual Motivators 0.9110 .535} \\
\hline Reciprocal & 3 & 0.900 & 0.750 \\
\hline Reputation & 3 & 0.895 & 0.741 \\
\hline Knowledge Self-Efficacy & 3 & 0.817 & 0.604 \\
\hline \multicolumn{4}{|l|}{ Peers Motivators 0.8660 .565} \\
\hline Peers' Attitude & 3 & 0.896 & 0.741 \\
\hline Peers' Interactivity & 3 & 0.874 & 0.698 \\
\hline \multicolumn{4}{|c|}{ Organizational Motivators 0.9430 .580} \\
\hline Management Support & 3 & 0.940 & 0.839 \\
\hline Culture & 3 & 0.903 & 0.756 \\
\hline Rewards & 3 & 0.927 & 0.808 \\
\hline Structure & 3 & 0.925 & 0.804 \\
\hline \multicolumn{4}{|c|}{ Technological Motivators 0.9540 .635} \\
\hline Ease of Use & 3 & 0.914 & 0.780 \\
\hline Technology Task Fit & 3 & 0.933 & 0.822 \\
\hline Security & 3 & 0.913 & 0.778 \\
\hline Usefulness & 3 & 0.948 & 0.858 \\
\hline Knowledge Sharing Usage & 5 & 0.931 & 0.730 \\
\hline
\end{tabular}

\section{Convergent Validity}

Apart from the assessment of the constructs' reliability, the average variance extracted (AVE) is used to measure the constructs' validity. The AVE values range from 0.535 to 0.858 , which are higher than the recommended threshold value of 0.5 , as recommended by Chin (1998). In addition, the indicators' outer loading demonstrates a satisfactory level of 0.70, as suggested by Chin (1998), except for item 
Know_Efficacy3 in the first-order and the following items in the second-order: Know_Efficacy2, Know_Efficacy3,Org_Culture1,Org_Rewards1, Org_Rewards2, Perceived_EOU2, Perceived_EOU3, and Perceived_Security1. However, these items were not deleted from the analysis of the model as they exceeded the minimum value of 0.50 as indicated by Hair et al. (2016). Instead, they were occasionally retained in the model to contribute to content validity. Table 3 shows the AVE for all the items listed in the model, and Appendix A shows the indicators' loadings.

\section{Discriminant Validity}

To verify discriminant validity, the Fornell and Larcker criterion was used to test the discriminant validity of the constructs (Hair et al., 2016). Both first-order and second-order constructs satisfy the discriminant validity condition that the square root of the average variance extracted (AVE) for each construct is larger than the inter-construct correlations in the model.

\section{Assessment of the Significance of the Structural Model}

The quality of the structural model can be assessed by the model's predictive capabilities represented by the R-squares $\left(\mathrm{R}^{2}\right)$ of the dependent latent variable and the directions and significance of the path coefficients of the independent variable (Chin, 1998). $\mathrm{R}^{2}$ indicates the amount of variance of the dependent variables impacted by the independent variables. Thus, the power of the research model is highly predictive if the $\mathrm{R}^{2}$ value is larger (Hair et al., 2016; Welschen, 2014). The results of the SmartPLS output show that the value is 0.474 , indicating that there is a $47.4 \%$ variance in knowledge workers to use ESM for KS. The adjusted $\mathrm{R}^{2}$ value can be considered as a moderate value of variance explained, as suggested by Chin (1998).

A path coefficient is used to estimate the structural model relationship, which represents the hypothesized relationships between constructs. In the partial least squares method, the bootstrap procedure is used to test the significance of path coefficients. The significance level of 5\% is used the most frequently by researchers (Hair et al., 2016). The results reveal that all first-order constructs were significant to their corresponding second-order constructs (individual motivators, organizational motivators, peer motivators, and technological motivators). However, technological motivators - the second-order construct - are the only significant construct for knowledge workers to use ESM for KS. The technological motivators have a strong significant relationship $(\beta=0.579 ; p$-value $=0.000)$ with sharing knowledge via ESM among knowledge workers within the telecommunications company because the $\mathrm{p}$-value $<0.001$; thus, $\mathrm{H} 4$ was supported. The significance of organizational motivators was not confirmed in this study $(\beta=0.188$; $p$-value $=0.145)$ regarding knowledge workers using ESM for KS; thus, H2 was not supported. Furthermore, the critical influence of individual motivators

Table 4. Main Study Model - Second-Order Constructs' Significance

\begin{tabular}{|c|c|c|c|c|c|c|}
\hline Construct & Path & B & t-static & P-value & Significance & Hypothesis \\
\hline $\begin{array}{l}\text { Individual } \\
\text { Motivators }\end{array}$ & $\begin{array}{l}\text { Individual } \\
\text { Motivators } ® \mathrm{KS} \\
\text { Usage }\end{array}$ & 0.150 & 1.312 & 0.190 & Not significant & $\begin{array}{l}\text { H1 is not } \\
\text { supported }\end{array}$ \\
\hline $\begin{array}{l}\text { Organizational } \\
\text { Motivators }\end{array}$ & $\begin{array}{l}\text { Organizational } \\
\text { Motivators } ® \mathrm{KS} \\
\text { Usage }\end{array}$ & 0.188 & 1.456 & 0.145 & Not significant & $\begin{array}{l}\mathrm{H} 2 \text { is not } \\
\text { supported }\end{array}$ \\
\hline Peers Motivators & $\begin{array}{l}\text { Peers Motivators } \\
\text { ®KS Usage }\end{array}$ & -0.165 & 0.971 & 0.332 & Not significant & $\begin{array}{l}\text { H3 is not } \\
\text { supported }\end{array}$ \\
\hline $\begin{array}{l}\text { Technological } \\
\text { Motivators }\end{array}$ & $\begin{array}{l}\text { Technological } \\
\text { Motivators } ® \mathrm{KS} \\
\text { Usage }\end{array}$ & 0.579 & 4.411 & 0.000 & Significant & $\begin{array}{l}\mathrm{H} 4 \text { is } \\
\text { supported }\end{array}$ \\
\hline
\end{tabular}


$(\beta=0.150 ; p$-value $=0.190)$ and peer motivators $(\beta=-0.165 ; p$-value $=0.332)$ were not detected in this study with a $95 \%$ significance level; thus, $\mathrm{H} 1$ and $\mathrm{H} 3$, respectively, were not supported. Table 4 shows the significance of the second-order constructs.

The study also assessed the direct effect of first-order constructs in sharing knowledge among knowledge workers. The results show only a direct significance in ease of use ( $\beta=0.140$; $p$-value $=0.000)$, technology task fit $(\beta=0.172 ; \mathrm{p}$-value $=0.000)$, security $(\beta=0.166 ; \mathrm{p}$-value $=0.000)$, and usefulness $(\beta=0.174$; $p$-value $=0.000)$ in sharing knowledge among knowledge workers using ESM, as indicated in Table 5.

Figure 3 shows a graphical representation of the main study model with loadings, path coefficient $(\beta)$ values, and an adjusted $R^{2}$ value.

Table 5. Main Study Model - First-Order Constructs' Significance in Sharing Knowledge Using ESM

\begin{tabular}{|l|l|l|l|l|}
\hline Construct & Path coefficient $(\boldsymbol{\beta})$ & t-static & p-value & Significance \\
\hline Ease of Use & 0.140 & 4.060 & 0.000 & Significant \\
\hline Management Support & 0.061 & 1.442 & 0.149 & Not significant \\
\hline Peers' Attitude & -0.096 & 0.977 & 0.329 & Not significant \\
\hline Peers' Interactivity & -0.090 & 0.977 & 0.329 & Not significant \\
\hline Reciprocal & 0.061 & 1.319 & 0.187 & Not significant \\
\hline Reputation & 0.058 & 1.313 & 0.189 & Not significant \\
\hline Technology Task Fit & 0.172 & 4.479 & 0.000 & Significant \\
\hline Culture & 0.052 & 1.458 & 0.145 & Not significant \\
\hline Knowledge Self-Efficacy & 0.052 & 1.289 & 0.198 & Not significant \\
\hline Rewards & 0.049 & 1.441 & 0.150 & Not significant \\
\hline Security & 0.166 & 4.396 & 0.000 & Significant \\
\hline Structure & 0.058 & 1.452 & 0.147 & Not significant \\
\hline Usefulness & 0.174 & 4.345 & 0.000 & Significant \\
\hline
\end{tabular}

\section{Further Analysis Results}

A further analysis was conducted by categorizing the KS through ESM into tacit KS and explicit KS, per Bock et al. (2005). In terms of tacit KS, the results reveal a significant influence in both organizational motivators $(\beta=0.263$; $p$-value $=0.036)$ and technological motivators $(\beta=0.618 ; p$-value $=0.000)$ among knowledge workers to use ESM for sharing tacit knowledge, as indicated in Figure 4 However, individual motivators $(\beta=0.035$; $p$-value $=0.755)$ and peer motivators $(\beta=-0.139$; $p$-value $=0.368)$ had an insignificant impact on sharing tacit knowledge through ESM. Adjusted $\mathrm{R}^{2}$ value indicated that there was a $50.3 \%$ variance, which can be described as a moderate value as recommended by Chin (1998), in knowledge workers' usage of ESM to share tacit knowledge.

In terms of the direct significance of first-order motivators on knowledge workers' usage of ESM to share tacit knowledge (Figure 4$)$, the results show that management support $(\beta=0.113$; $p$-value $=$ $0.037)$, culture $(\beta=0.070$; $p$-value $=0.037)$, and structure $(\beta=0.108 ; p$-value $=0.035)$ had a significant influence among knowledge workers sharing tacit knowledge using ESM in a telecommunications company. In addition, technology task fit $(\beta=0.241$; $p$-value $=0.000)$, security $(\beta=0.177$; $p$-value $=0.000)$, and usefulness $(\beta=0.255 ; \mathrm{p}$-value $=0.000)$ were significant constructs in sharing tacit knowledge through ESM. 
Figure 4 presents a graphical representation of the enhanced model with tacit KS showing constructs' outer loading values, $\beta$-values, and an adjusted $\mathrm{R}^{2}$ of the dependent variable.

In terms of explicit KS through ESM, the results show a significant positive relationship between the construct of technological motivators $(\beta=0.484$; $p$-value $=0.001)$ and sharing explicit knowledge through ESM, thus providing support for $\mathrm{H} 4$. However, no significance was found for individual motivators $(\beta=0.063$; $p$-value $=0.627)$, organizational motivators $(\beta=0.116$; $p$-value $=0.400)$, or peer motivators $(\beta=-0.085$; $p$-value $=0.633$ ) on knowledge workers' usage of ESM to share explicit knowledge; therefore, $\mathrm{H} 1, \mathrm{H} 2$, and $\mathrm{H} 3$, respectively, were not supported (Figure 4). In terms of the direct significance of first-order constructs in sharing explicit knowledge between knowledge workers using ESM, as presented in Figure 5, technology task fit $(\beta=0.193$; $p$-value $=0.001)$, security $(\beta=0.139$; $\mathrm{p}$-value $=0.001)$, and usefulness $(\beta=0.199 ; \mathrm{p}$-value $=0.001)$ were the only significant constructs in sharing explicit knowledge.

Figure 3. A Graphical Representation of Main Study Model

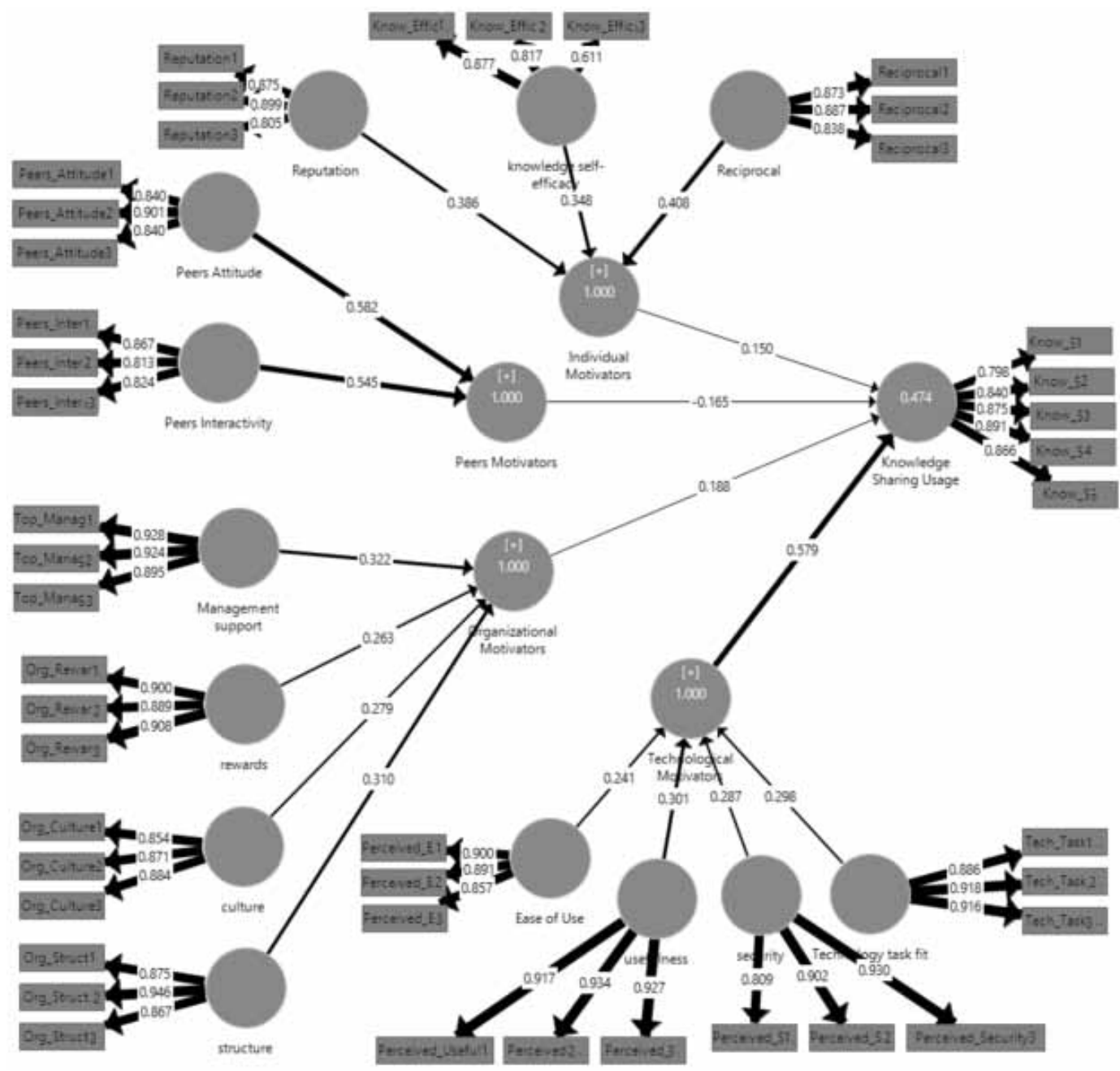


International Journal of Knowledge Management Volume $18 \cdot$ Issue 1

Figure 4. A Graphical Representation of the Tacit Knowledge Sharing Model

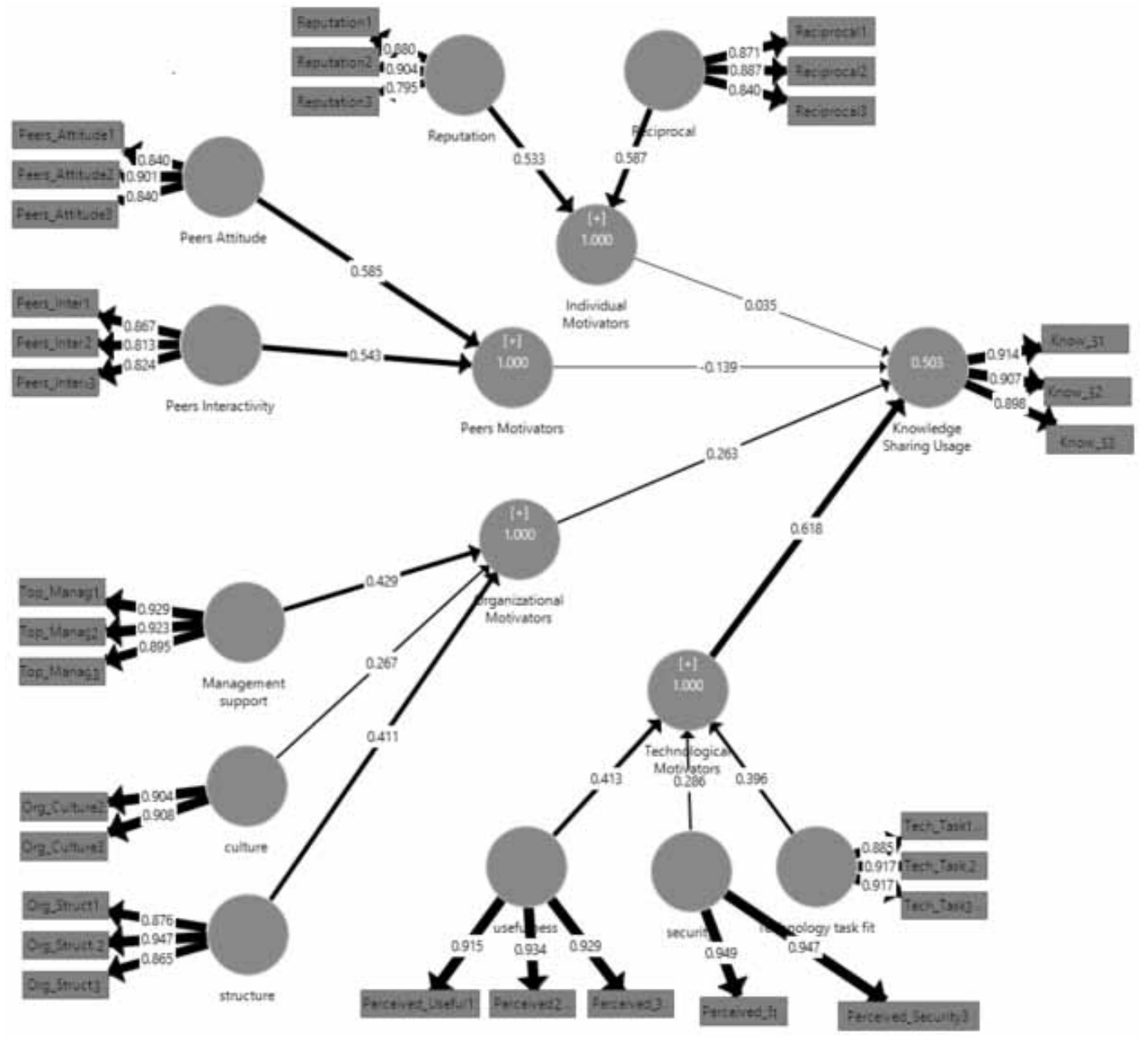




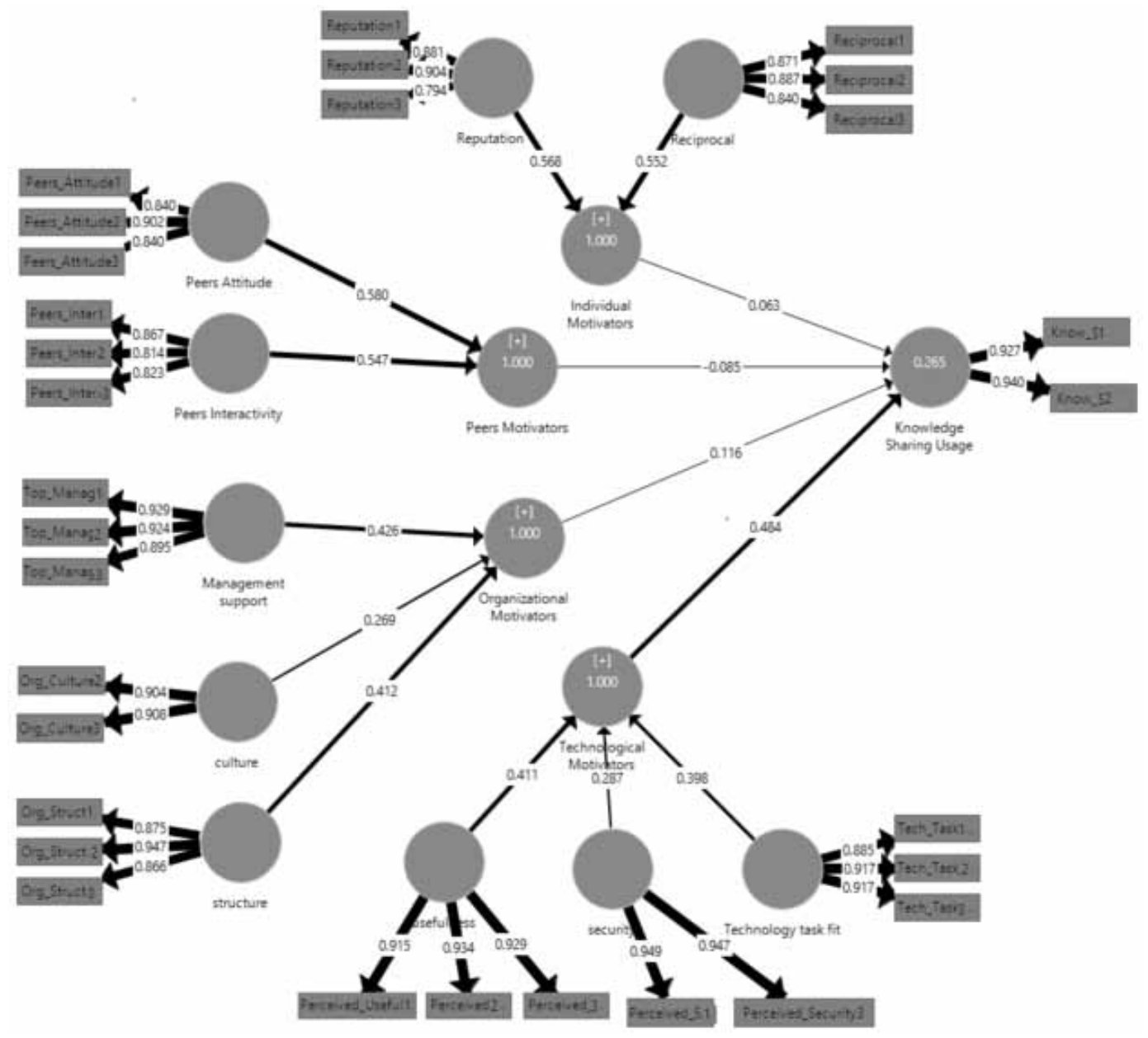

\section{CONCLUSION AND RECOMMENDATIONS}

\section{Summary of Findings}

This study aimed to investigate the motivational factors of knowledge workers' usage of enterprise social media (ESM) to share knowledge in one of the leading telecommunications companies in Oman. The study framework unveiled four main motivator categories: individual motivators, organizational motivators, peer motivators, and technological motivators.

The results of the main model showed that technological motivators (including perceived usefulness, perceived ease of use, technology task fit and perceived security) had a direct effect on sharing knowledge using ESM among knowledge workers in a telecommunications company. However, the study was unable to detect the significance of other motivators (individual motivators, peer motivators, and organizational motivators.

Further analysis on the type of shared knowledge (tacit versus explicit) indicated that technological motivators (perceived usefulness, technology task fit, and perceived security) and organizational motivators (management support, organizational culture, and organizational structure) significantly impact knowledge workers to share tacit knowledge through ESM rather than explicit knowledge. 
One potential explanation for this finding is that organizational motivators play an important role for knowledge workers in telecommunications companies to share tacit knowledge with their colleagues. However, peer motivators and individual motivators did not show significance in sharing tacit knowledge through ESM platforms. Thus, more investigation might be required regarding these two categorical motivators.

\section{Implications for Practice}

The study findings help managers - and specifically, telecommunications managers - to explore the motivators of using ESM for KS. In addition, this study provides practitioners with insights into actively investing in human resources, thereby fostering KS through ESM compared to traditional KM systems. Therefore, a comprehensive understanding of the motivators allows the company to make better decisions.

The study has confirmed that technological motivators are significant in determining the actual usage of knowledge workers in KS through ESM. This implies that telecommunications managers need to formulate and build their KS strategies through ESM around technological motivational factors such as perceived usefulness, perceived ease of use, technology task fit, and perceived security. This can be done by involving employees - and specifically, experts-who have more experience in the company when selecting which ESM platform to use. Furthermore, perceived security of using ESM for KS within telecommunications companies is a major concern that managers should carefully address. This can be done by developing strategies, privacy statements, and data protection guidelines to ensure that ESM platforms are secured and protected against unauthorized access. Thus, it is essential to involve the security strategy department or security representatives within the company when proposing a new system. Accordingly, once knowledge workers perceive that ESM is secure, they will establish trust in using ESM for KS.

The study also revealed that organizational motivators (management support, organizational culture, and organizational structure) in addition to technological motivators are important in sharing tacit knowledge through ESM. Tacit knowledge resides within the minds of the employees and is difficult to articulate; thus, managers have to leverage their knowledge workers' tacit knowledge. Chen et al. (2018) further clarified this point by emphasizing the need for organizations to adopt effective and efficient strategies to encourage tacit KS behaviors, owing to their criticality in the KS process. Therefore, the decision makers and management at telecommunications companies should provide a motivated culture characterized by openness, fairness, and innovation, for example, by giving enough space to allow their employees to innovate and a flexible organizational structure that allows knowledge to flow smoothly. Finally, it is crucial that top managers look for creative and innovative ways to engage their employees in fostering KS using ESM, as supervisors should encourage the process and highlight potential benefits.

\section{Implications for Researchers}

This study has some implications for researchers through its manifold contributions. First, it fills the gap in the literature by emphasizing the motivators of knowledge workers to use enterprise social media platforms (ESMPs) for KS in the workplace. As indicated earlier, the literature highlights the need for social media (Asrar-ul-Haq \& Anwar, 2016; Razmerita et al., 2016; Laitinen \& Sivunen, 2021) and enterprise social networks (Aboelmaged, 2018) in promoting KS; the study demonstrated the importance of such investigation for also a developing country. It contributes to the literature of ESM by providing deep insights into the motivators that impact knowledge workers' usage of ESM platforms for KS within the telecommunications context, in general, and based on the type of shared knowledge, whether it is explicit or tacit. Thus, this study contributes towards serving as a theoretical foundation for other researchers by testing the research framework in different contexts. 


\section{Limitations and Future Research}

This study has some limitations. Firstly, the study sample size was 100 valid responses. Even though the sample size was acceptable for this study model, future research should consider a larger sample size to enhance the significance of the results. Secondly, generalizing the results should be cautioned because they may differ in different organizational contexts due to cultural differences (Kankanhalli et al., 2005). Therefore, future research could re-test the study models in other contexts, for example, by comparing the actual usage of ESM for KS in different organizations and countries to enhance external validity. Future studies may focus on the impact of using ESM platforms for KS on employee productivity. 


\section{REFERENCES}

Aboelmaged, M. G. (2018). Knowledge sharing through enterprise social network (ESN) systems: Motivational drivers and their impact on employees' productivity. Journal of Knowledge Management, 22(2), 362-383. doi:10.1108/JKM-05-2017-0188

Abu-Salih, B., Bremie, B., Wongthongtham, P., Duan, K., Issa, T., Chan, K. Y., . . Albahlal, A. (2019, March). Social credibility incorporating semantic analysis and machine learning: a survey of the state-of-the-art and future research directions. In Workshops of the International Conference on Advanced Information Networking and Applications (pp. 887-896). Springer. doi:10.1007/978-3-030-15035-8_87

Ahmed, Y. A., Ahmad, M. N., \& Zakaria, N. H. (2016). Towards exploring factors that influence social mediabased knowledge sharing intentions in disaster management. Journal of Theoretical and Applied Information Technology, 88(3), 487-498.

Akram, T., Lei, S., Haider, M. J., Hussain, S. T., \& Puig, L. C. M. (2017). The effect of organizational justice on knowledge sharing: Empirical evidence from the Chinese telecommunications sector. Journal of Innovation \& Knowledge, 2(3), 134-145. doi:10.1016/j.jik.2016.09.002

Al-Alawi, A. I., Al-Marzooqi, N. Y., \& Mohammed, Y. F. (2007). Organizational culture and knowledge sharing: Critical success factors. Journal of Knowledge Management, 11(2), 22-42. doi:10.1108/13673270710738898

Al-Busaidi, K. A. (2014). SWOT of social networking sites for group work in government organizations: An exploratory Delphi study from IT managers' perspective. VINE Journal of Information and Knowledge Management Systems, 44(1), 121-139.

Al-Busaidi, K. A. (2015). Inter-Organizational Knowledge Sharing System in the Health Sector: Physicians' Perspective. International Journal of Knowledge Management, 11(3), 37-54. doi:10.4018/IJKM.2015070103

Al-Busaidi, K. A., \& Olfman, L. (2017). Knowledge sharing through inter-organizational knowledge sharing systems. VINE Journal of Information and Knowledge Management Systems, 47(1), 110-136. doi:10.1108/ VJIKMS-05-2016-0019

AlRowaily, K., \& Alsadhan, A. O. (2012). Integration of Knowledge Management system in Telecommunication: A case Study of Saudi Telecom. International Journal of Computer Science and Network Security, 12(11), 42-53.

Asrar-ul-Haq, M., \& Anwar, S. (2016). A systematic review of knowledge management and knowledge sharing: Trends, issues, and challenges. Cogent Business \& Management, 3(1), 1127744. doi:10.1080/23311975.2015 .1127744

Becerra-Fernandez, I., \& Sabherwal, R. (2014). Knowledge management: Systems and processes. Routledge.

Bock, G.-W., Zmud, R. W., Kim, Y.-G., \& Lee, J.-N. (2005). Behavioral intention formation in knowledge sharing: Examining the roles of extrinsic motivators, social-psychological forces, and organizational climate. Management Information Systems Quarterly, 29(1), 87-111. doi:10.2307/25148669

Borges, R., Bernardi, M., \& Petrin, R. (2019). Cross-country findings on tacit knowledge sharing: Evidence from the Brazilian and Indonesian IT workers. Journal of Knowledge Management, 23(4), 742-762. doi:10.1108/ JKM-04-2018-0234

Bughin, J., Chui, M., \& Manyika, J. (2012). Capturing business value with social technologies. The McKinsey Quarterly, 4(1), 72-80.

Cabrera, A., Collins, W. C., \& Salgado, J. F. (2006). Determinants of individual engagement in knowledge sharing. International Journal of Human Resource Management, 17(2), 245-264. doi:10.1080/09585190500404614

Cabrera, E. F., \& Cabrera, A. (2005). Fostering knowledge sharing through people management practices. International Journal of Human Resource Management, 16(5), 720-735. doi:10.1080/09585190500083020

Chen, H., Baptista Nunes, M., Ragsdell, G., \& An, X. (2018). Extrinsic and intrinsic motivation for experience grounded tacit knowledge sharing in Chinese software organisations. Journal of Knowledge Management, 22(2), 478-498. doi:10.1108/JKM-03-2017-0101 
Chennamaneni, A., Teng, J. T., \& Raja, M. (2012). A unified model of knowledge sharing behaviours: Theoretical development and empirical test. Behaviour \& Information Technology, 31(11), 1097-1115. doi:10.1080/0144 929X.2011.624637

Chin, C. P.-Y., Evans, N., \& Choo, K.-K. R. (2015). Exploring factors influencing the use of enterprise social networks in multinational professional service firms. Journal of Organizational Computing and Electronic Commerce, 25(3), 289-315. doi:10.1080/10919392.2015.1058118

Chin, W. W. (1998). The partial least squares approach to structural equation modeling. Modern Methods for Business Research, 295(2), 295-336.

Chin Wei, C., Siong Choy, C., \& Kuan Yew, W. (2009). Is the Malaysian telecommunication industry ready for knowledge management implementation? Journal of Knowledge Management, 13(1), 69-87. doi:10.1108/13673270910931170

Choudrie, J., \& Zamani, E. D. (2016). Understanding individual user resistance and workarounds of enterprise social networks: The case of Service Ltd. Journal of Information Technology, 31(2), 130-151. doi:10.1057/ jit.2016.9

Creswell, J. W. (2003). Research design: Qualitative, quantitative, and mixed method approaches (2nd ed.). SAGE, c.

Cummings, J. N. (2004). Work groups, structural diversity, and knowledge sharing in a global organization. Management Science, 50(3), 352-364. doi:10.1287/mnsc.1030.0134

Davenport, T. H., \& Prusak, L. (1998). Working knowledge: How organizations manage what they know. Harvard Business Press.

Davis, F. D., Bagozzi, R. P., \& Warshaw, P. R. (1992). Extrinsic and intrinsic motivation to use computers in the workplace. Journal of Applied Social Psychology, 22(14), 1111-1132. doi:10.1111/j.1559-1816.1992.tb00945.x

de Almeida, F. C., Lesca, H., \& Canton, A. W. (2016). Intrinsic motivation for knowledge sharing-competitive intelligence process in a telecom company. Journal of Knowledge Management, 20(6), 1282-1301. doi:10.1108/ JKM-02-2016-0083

Drucker, P. F. (1994). The age of social transformation. Academic Press.

Drucker, P. F. (1999). Knowledge-worker productivity: The biggest challenge. California Management Review, 41(2), 79-94. doi:10.2307/41165987

Ghobadi, S., \& D’Ambra, J. (2012). Knowledge sharing in cross-functional teams: A coopetitive model. Journal of Knowledge Management, 16(2), 285-301. doi:10.1108/13673271211218889

Gold, A. H., Malhotra, A., \& Segars, A. H. (2001). Knowledge management: An organizational capabilities perspective. Journal of Management Information Systems, 18(1), 185-214. doi:10.1080/07421222.2001.11045669

Goodhue, D. L., \& Thompson, R. L. (1995). Task-technology fit and individual performance. Management Information Systems Quarterly, 19(2), 213-236. doi:10.2307/249689

Hair, J. F., Ringle, C. M., \& Sarstedt, M. (2011). PLS-SEM: Indeed a silver bullet. Journal of Marketing Theory and Practice, 19(2), 139-152. doi:10.2753/MTP1069-6679190202

Harden, G. (2012). Knowledge sharing in the workplace: A social networking site assessment. Paper presented at the System Science (HICSS), 2012 45th Hawaii International Conference on, Maui, HI. doi:10.1109/ HICSS.2012.408

Hau, Y. S., Kim, B., Lee, H., \& Kim, Y.-G. (2013). The effects of individual motivations and social capital on employees' tacit and explicit knowledge sharing intentions. International Journal of Information Management, 33(2), 356-366. doi:10.1016/j.jinfomgt.2012.10.009

Hsu, M. H., \& Chang, C. M. (2014). Examining interpersonal trust as a facilitator and uncertainty as an inhibitor of intra-organisational knowledge sharing. Information Systems Journal, 24(2), 119-142. doi:10.1111/isj.12000 
Hung, S.-Y., Lai, H.-M., \& Chang, W.-W. (2011). Knowledge-sharing motivations affecting R\&D employees' acceptance of electronic knowledge repository. Behaviour \& Information Technology, 30(2), 213-230. doi:10 $.1080 / 0144929 X .2010 .545146$

Ibidunni, A. S., Olokundun, A. M., Falola, H. O., \& Ogunnaike, O. (2018). Descriptive Analysis of Organisational Knowledge Utilization in Nigeria's Telecommunication Industry: A Focus on Managerial Implications. Academy of Strategic Management Journal, 17(2), 1-7.

Iqbal, S. (2016). Employees' Perception Regarding the Role of Specific HRM Practices in Knowledge Intensive Firms. International Journal of Social Sciences and Management, 3(4), 246-255. doi:10.3126/ijssm.v3i4.15888

Iqbal, S., Toulson, P., \& Tweed, D. (2015). Employees as performers in knowledge intensive firms: Role of knowledge sharing. International Journal of Manpower, 36(7), 1072-1094. doi:10.1108/IJM-10-2013-0241

Javaid, J., Soroya, S., \& Mahmood, K. (2020). Impact of personal and organizational factors on knowledge sharing attitude of university teachers in Pakistan. The Electronic Library, 38(2), 317-336. doi:10.1108/EL-05-2019-0121

Jennex, M. E., \& Zyngier, S. (2007). Security as a contributor to knowledge management success. Information Systems Frontiers, 9(5), 493-504. doi:10.1007/s10796-007-9053-4

Kanaan, R., \& Gharibeh, A. H. (2013). The impact of knowledge sharing enablers on knowledge sharing capability: An empirical study on Jordanian telecommunication firms. European Scientific Journal, ESJ, 9(22), 237-258.

Kankanhalli, A., Tan, B. C., \& Wei, K.-K. (2005). Contributing knowledge to electronic knowledge repositories: An empirical investigation. Management Information Systems Quarterly, 29(1), 113-143. doi:10.2307/25148670

Lacosta, A., \& Thomas, C. (2020, November). Enterprise social networking Knowledge Management tools and knowledge dynamics. In 2020 IEEE International Conference on Technology Management, Operations and Decisions (ICTMOD) (pp. 1-8). IEEE.

Laitinen, K., \& Sivunen, A. (2021). Enablers of and constraints on employees' information sharing on enterprise social media. Information Technology \& People, 34(2), 642-665. doi:10.1108/ITP-04-2019-0186

Lee, T. W., \& Maurer, S. D. (1997). The retention of knowledge workers with the unfolding model of voluntary turnover. Human Resource Management Review, 7(3), 247-275. doi:10.1016/S1053-4822(97)90008-5

Leonardi, P. M. (2017). The social media revolution: Sharing and learning in the age of leaky knowledge. Information and Organization, 27(1), 47-59. doi:10.1016/j.infoandorg.2017.01.004

Leonardi, P. M., Huysman, M., \& Steinfield, C. (2013). Enterprise social media: Definition, history, and prospects for the study of social technologies in organizations. Journal of Computer-Mediated Communication, 19(1), 1-19. doi:10.1111/jcc4.12029

Lin. (2007). Effects of extrinsic and intrinsic motivation on employee knowledge sharing intentions. Journal of Information Science, 33(2), 135-149.

Maheshwari, B., Sarrion, M., Motiani, M., O’Sullivan, S., \& Chandwani, R. (2021). Exploration of factors affecting the use of Web 2.0 for knowledge sharing among healthcare professionals: An Indian perspective. Journal of Knowledge Management, 25(3), 545-558. doi:10.1108/JKM-02-2020-0105

Majchrzak, A., Faraj, S., Kane, G. C., \& Azad, B. (2013). The contradictory influence of social media affordances on online communal knowledge sharing. Journal of Computer-Mediated Communication, 19(1), 38-55. doi:10.1111/jcc4.12030

Masa'deh, R., Gharaibeh, A., Maqableh, M., \& Karajeh, H. (2013). An empirical study of antecedents and outcomes of knowledge sharing capability in Jordanian telecommunication firms: A structural equation modeling approach. Life Science Journal, 10(4), 2284-2296.

Meneghello, J., Thompson, N., Lee, K., Wong, K. W., \& Abu-Salih, B. (2020). Unlocking social media and user generated content as a data source for knowledge management. International Journal of Knowledge Management, 16(1), 101-122. doi:10.4018/IJKM.2020010105

Nguyen, M., Malik, A., \& Sharma, P. (2021). How to motivate employees to engage in online knowledge sharing? Differences between posters and lurkers. Journal of Knowledge Management, 25(7), 1811-1831. doi:10.1108/ JKM-08-2020-0649 
Nguyen, T. M., \& Prentice, C. (2020). Reverse relationship between reward, knowledge sharing and performance. Knowledge Management Research and Practice, 1-12. doi:10.1080/14778238.2020.1821588

Nielsen, P., \& Razmerita, L. (2014). Motivation and knowledge sharing through social media within Danish organizations. Paper presented at the International Working Conference on Transfer and Diffusion of IT, Berlin, Germany. doi:10.1007/978-3-662-43459-8_13

Nonaka, I., \& Takeuchi, H. (1995). The Knowledge-Creating Company: How Japanese Companies Create the Dynamics of Innovation. Oxford University Press.

Oh, S., \& Syn, S. Y. (2015). Motivations for sharing information and social support in social media: A comparative analysis of Facebook, Twitter, Delicious, YouTube, and Flickr. Journal of the Association for Information Science and Technology, 66(10), 2045-2060. doi:10.1002/asi.23320

Pérez-González, D., Trigueros-Preciado, S., \& Popa, S. (2017). Social media technologies' use for the competitive information and knowledge sharing, and its effects on industrial SMEs' innovation. Information Systems Management, 34(3), 291-301. doi:10.1080/10580530.2017.1330007

Rahman, N. (2020). Understanding the Impact of Knowledge Sharing through Enterprise Social Networking (ESN) on Service Innovation. Proceedings of the 53rd Hawaii International Conference on System Sciences. doi:10.24251/HICSS.2020.600

Razmerita, L., Kirchner, K., \& Nielsen, P. (2016). What factors influence knowledge sharing in organizations? A social dilemma perspective of social media communication. Journal of Knowledge Management, 20(6), 1225-1246. doi:10.1108/JKM-03-2016-0112

Rode, H. (2016). To share or not to share: The effects of extrinsic and intrinsic motivations on knowledge-sharing in enterprise social media platforms. Journal of Information Technology, 31(2), 152-165. doi:10.1057/jit.2016.8

Rozaidi, N. A., Gibbs, J. L., \& Eisenberg, J. (2017). Accept or Reject? Predicting Ideation Outcomes through Enterprise Social Media. Paper presented at the SHS Web of Conferences, Kuala Lumpur, Malaysia. doi:10.1051/ shsconf/20173300053

Salisbury, W. D., Pearson, R. A., Pearson, A. W., \& Miller, D. W. (2001). Perceived security and World Wide Web purchase intention. Industrial Management \& Data Systems, 101(4), 165-177. doi:10.1108/02635570110390071

Saunders, M., Lewis, P., \& Thornhill, A. (2012). Research methods for business students (6th ed.). Pearson.

Scuotto, V., Del Giudice, M., \& Obi Omeihe, K. (2017). SMEs and mass collaborative knowledge management: Toward understanding the role of social media networks. Information Systems Management, 34(3), 280-290. doi:10.1080/10580530.2017.1330006

Singh, A. K., \& Sharma, V. (2011). Knowledge management antecedents and its impact on employee satisfaction: A study on Indian telecommunication industries. The Learning Organization, 18(2), 115-130. doi:10.1108/09696471111103722

Stenius, M., Haukkala, A., Hankonen, N., \& Ravaja, N. (2017). What Motivates Experts to Share? A Prospective Test of the Model of Knowledge-Sharing Motivation. Human Resource Management, 56(6), 871-885. doi:10.1002/hrm.21804

Stephen, I. A., Mary, I. O., Oluremi, O. A., William, A. A., \& Ayodele, O. M. (2018). Examining the relationship between tacit knowledge of individuals and customer satisfaction. Academy of Entrepreneurship Journal, 24(1), $1-20$.

Strouse, K. G. (2001). Strategies for success in the new telecommunications marketplace. Artech House Publishers.

Suraj, O. A. (2016). Managing Telecommunications for Development: An Analysis of Intellectual Capital in Nigerian Telecommunication Industry. Journal of Information \& Knowledge Management, 15(01), 1650010. doi:10.1142/S0219649216500106

Susanty, A., Salwa, M., Chandradini, A., Evanisa, F., \& Iriani, N. (2016). Knowledge Sharing and Implementation of Its Enabling Factors (A Case Study of Three Types of Company in Indonesia). Pertanika Journal of Social Sciences \& Humanities, 24(S), 239-254. 
van Dijk, A., Hendriks, P., \& Romo-Leroux, I. (2016). Knowledge sharing and social capital in globally distributed execution. Journal of Knowledge Management, 20(2), 327-343. doi:10.1108/JKM-07-2015-0268

Venkatesh, V., \& Davis, F. D. (2000). A theoretical extension of the technology acceptance model: Four longitudinal field studies. Management Science, 46(2), 186-204. doi:10.1287/mnsc.46.2.186.11926

Wang, T., Jung, C.-H., Kang, M.-H., \& Chung, Y.-S. (2014). Exploring determinants of adoption intentions towards Enterprise 2.0 applications: An empirical study. Behaviour \& Information Technology, 33(10), 10481064. doi:10.1080/0144929X.2013.781221

Wei, C., Pitafi, A. H., Kanwal, S., Ali, A., \& Ren, M. (2020). Improving employee agility using enterprise social media and digital fluency: Moderated mediation model. IEEE Access: Practical Innovations, Open Solutions, 8, 68799-68810. doi:10.1109/ACCESS.2020.2983480

Welschen, J. E. (2014). An investigation of the impact of extrinsic and intrinsic motivators on organisational knowledge sharing (Master of Commerce Master Thesis). University of Canterbury, New Zealand. (ACIS 690)

Xu, J., \& Quaddus, M. (2007). Exploring the factors influencing end users' acceptance of knowledge management systems: Development of a research model of adoption and continued use. Journal of Organizational and End User Computing, 19(4), 57-79. doi:10.4018/joeuc.2007100104

Yeo, R. K., \& Gold, J. (2014). Knowledge sharing attitude and behaviour in Saudi Arabian organisations: Why trust matters. International Journal of Human Resources Development and Management, 14(1-3), 97-118. doi:10.1504/IJHRDM.2014.068082

Zhang, X., \& Jiang, J. Y. (2015). With whom shall I share my knowledge? A recipient perspective of knowledge sharing. Journal of Knowledge Management, 19(2), 277-295. doi:10.1108/JKM-05-2014-0184 


\section{APPENDIX}

Table 6. Study's Constructs indicators and their loading

\begin{tabular}{|c|c|}
\hline Constructs' indicator & Loading \\
\hline \multicolumn{2}{|l|}{ Explicit Knowledge sharing - Adapted from Bock et al. (2005) } \\
\hline $\begin{array}{l}\text { 1. I use ESM to share my work reports and official documents with colleagues in my organization more frequently } \\
\text { 2. I always use ESM to provide my manuals, methodologies and models to colleagues in my organization } \\
\text { Tacit Knowledge sharing - Adapted from Bock et al. (2005) }\end{array}$ & 0.798 \\
\hline 1. I use ESM to share my experience and knowhow from work with other colleagues in my organization more frequently in the future & 0.875 \\
\hline $\begin{array}{l}\text { 2. I always use ESM to provide my know-where or know-whom at the request of other colleagues in my organization } \\
\text { 3. I try to use ESM to share my expertise from my education or training with other colleagues in my organization in a more effective way } \\
\text { than without ESM. }\end{array}$ & 0.891 \\
\hline \multicolumn{2}{|l|}{ Individual Motivators } \\
\hline \multicolumn{2}{|l|}{ Reputation - Adapted from Venkatesh and Davis (2000) } \\
\hline 1. People who share knowledge have more prestige than those who do not & 0.875 \\
\hline 2. People who share knowledge have a high profile & 0.899 \\
\hline 3. Sharing professional knowledge is a status symbol in my company & 0.805 \\
\hline \multicolumn{2}{|l|}{ Knowledge self-efficacy - Adapted from Kankanhalli et al. (2005) } \\
\hline 1. I have confidence in my ability to provide knowledge through ESM that others in my company consider valuable & 0.877 \\
\hline 2. I have the expertise needed to provide valuable knowledge through ESM for my company & 0.817 \\
\hline 3. Most other employees in my organization can provide more valuable knowledge than I can & 0.611 \\
\hline \multicolumn{2}{|l|}{ Enjoyment in helping others - Adapted from Kankanhalli et al. (2005) } \\
\hline 1. I enjoy helping colleagues by sharing my knowledge through ESM. & a \\
\hline 2. It feels good to help my colleagues by sharing my knowledge to solve their work related problems through ESM. & a \\
\hline 3. Sharing my knowledge with colleagues through ESM is pleasurable. & a \\
\hline \multicolumn{2}{|l|}{ Reciprocal benefits - Adapted from H.-F. Lin (2007a) } \\
\hline 1. When I share my knowledge with colleagues through the ESM, I strengthen ties between members of the organization and myself. & 0.873 \\
\hline 2. When I share my knowledge with colleagues through the ESM, I expect to receive knowledge in return when necessary. & 0.887 \\
\hline 3. When I share my knowledge with colleagues through the ESM, I believe that my future requests for knowledge will be answered. & 0.838 \\
\hline \multicolumn{2}{|l|}{ Peers Motivators } \\
\hline \multicolumn{2}{|l|}{ Social interaction - Adapted from van Dijk et al. (2016) } \\
\hline 1. I know some colleagues from different departments and across the organization on a personal level. & a \\
\hline 2. I spend a lot of time interacting with some colleagues from different departments. & a \\
\hline 3. I maintain close working relationships with some colleagues from different departments. & a \\
\hline \multicolumn{2}{|l|}{ Peers trust-Adapted from Al-Alawi et al. (2007) \& (last: Kankanhalli et al. (2005)) } \\
\hline 1. Most of my colleagues are people whom I know well and thus are considered trustworthy. & a \\
\hline 2. I have not been previously harmed as a result of sharing my knowledge with my colleagues. & a \\
\hline
\end{tabular}




\section{Table 6. Continued}

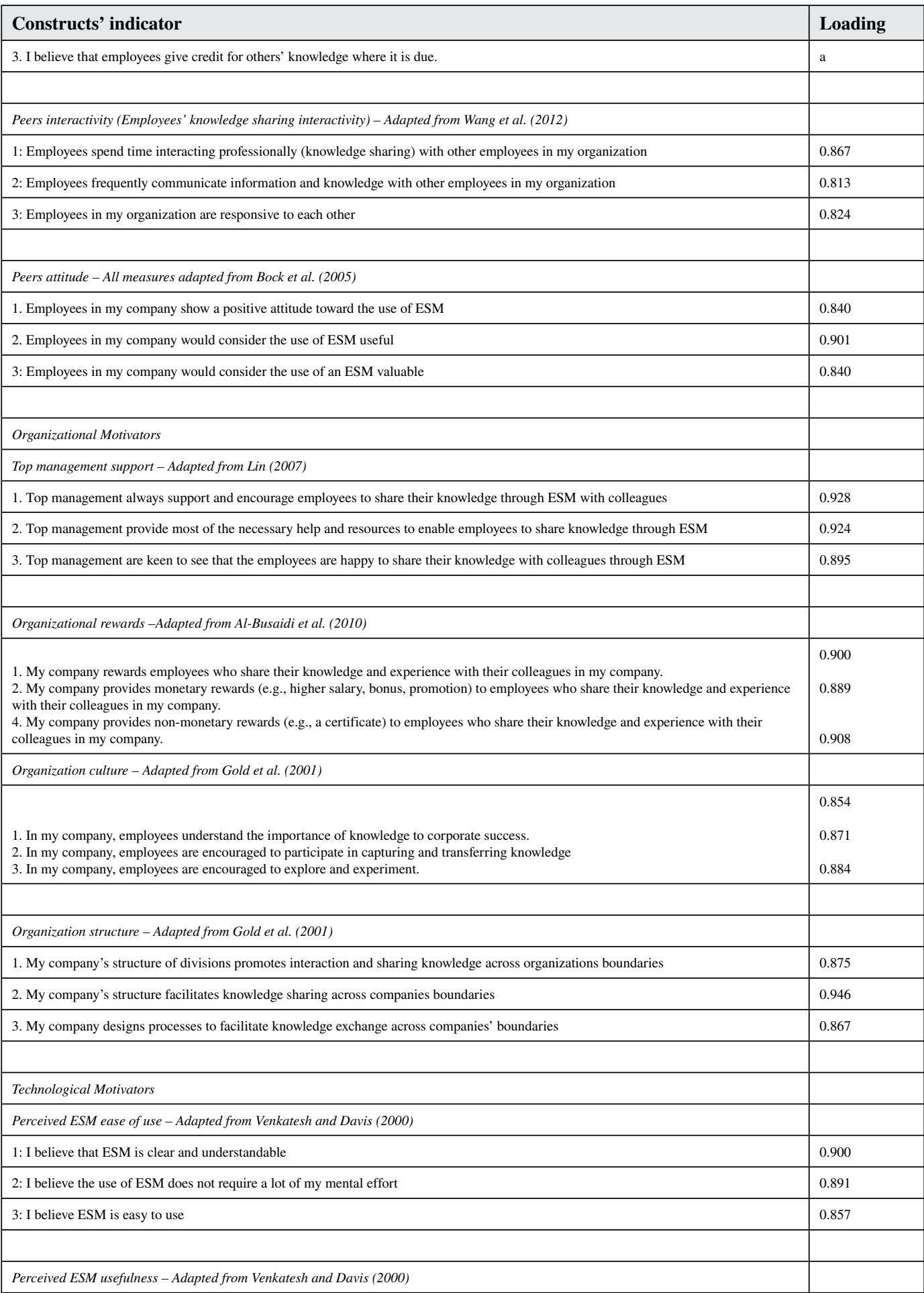


Table 6. Continued

\begin{tabular}{|c|c|}
\hline Constructs' indicator & Loading \\
\hline 1. I believe the use of ESM improves my performance at my work & 0.917 \\
\hline 2. I believe the use of ESM increases my productivity at my work & 0.934 \\
\hline 3. I believe the use of ESM enhances the effectiveness of my work & 0.927 \\
\hline \multicolumn{2}{|l|}{ Perceived ESM security - Adapted from Salisbury et al. (2001) } \\
\hline 1. I would feel secure sharing sensitive information through ESM & 0.809 \\
\hline 2. I would feel secure sharing my knowledge through ESM & 0.902 \\
\hline 3. Overall, ESM would be a safe place to transmit information and knowledge & 0.930 \\
\hline \multicolumn{2}{|l|}{ Technology task fit - Adapted from Moore and Benbasat (1991) } \\
\hline 2. Sharing knowledge through ESM is pretty much I need to carry out my tasks. & 0.886 \\
\hline 2. Sharing knowledge through ESM is completely compatible with my current work situation. & 0.918 \\
\hline 3. Sharing knowledge with employees through ESM fits my current needs. & 0.916 \\
\hline
\end{tabular}

Hajir Al Mawali is a graduate of MSc. in Information Systems from Sultan Qaboos University, Muscat, Oman (2019). From 2011 to 2019, she was working in a telecommunication company as a programmer and has been involved in developing different services and applications. Currently, she is working in the aviation sector as systems integration senior specialist. Her research interest includes the application of social media for organizational knowledge management.

Kamla Ali Al-Busaidi is a Professor of Information Systems at Sultan Qaboos University (SQU) in Oman. She received her PhD in Management Information Systems from Claremont Graduate University in California. Her research interests include knowledge management systems, learning management systems, knowledge economy and ICT investments. She has published articles in several international conference proceedings, book chapters, and journals. She held the Head of Information Systems Department from September 2015 to September 2018. She served as a session chair, organizing member and/or a reviewer for several local, regional, and international conferences, and as a reviewer, guest editor, and editorial member for several international journals. 